\title{
First Line Nurse Managers' Attributes and Work Stress Levels at Assiut University Hospitals
}

\author{
Noura Alsayed Esmail ${ }^{1}$, Samah Mohamed Abdalla ${ }^{2}, \&$ Amal Sayed Mohamed $^{3}$ \\ ${ }^{1 .}$ Demonstrator of Nursing Administration, Faculty of Nursing Assiut University, Egypt. \\ ${ }^{2 .}$ Prof of Nursing Administration, Faculty of Nursing Assiut University, Egypt. \\ ${ }^{3 .}$ Assist. Prof of Nursing Administration, Faculty of Nursing Assiut University, Egypt.
}

\begin{abstract}
Background: Not all the first line nurse managers have the same levels of leadership attributes so that being effective or ineffective nurse managers depends on the level of attributes she/he has. Aim: Determining the first line nurse managers' attributes and work stress level. Study design: Descriptive research design was used. Setting: Conducted at Assiut University Hospitals. Subject: First line nurse managers no.= 77 Methods: The data were collected using two tools; I- Structured self-administer questionnaire including; a) Personal data sheet, b) Assertiveness scale, c) Personal accountability checklist, d) Johari Window Questionnaire, and e) Protective Nursing Advocacy Scale II- Perceived work stress scale. Results: The study revealed that the highest percent of the first line nurse managers were not-assertive $\mathbf{( 7 2 . 7 \%}$ ), having high level of accountability $\mathbf{( 5 9 . 8 \% )}$, had open level of awareness $(\mathbf{1 6 . 9 \%})$, advocating others $(\mathbf{8 5 . 7 \%})$, and had moderate level of stress $(\mathbf{8 3 . 1 \%})$.Conclusion: There was negative relation between the first line nurse managers' attributes and work stress level. Recommendation: Implementing continuous educational programs for nurse managers to improve nurse awareness, and assertiveness
\end{abstract}

\section{Keywords: Nurse Managers, Attributes \& Work stress.}

\section{Introduction}

Nurse managers assumes direct responsibility for clinical area she/ he supervises. Nurse manager lies among top, middle and first line management position, supervises direct care providers in addition the same time nurse managers are accountable to nursing care provided by nursing staffs (Harris, 2015). Verghese (2016) added that all the nurse managers carry out the managerial functions of planning, organizing, assembling resources and controlling. Throughout performing these functions, nurse managers fulfill their designated roles in the organizations, so that, these roles are defined as behaviors or activities associated with managerial positions which give them the authority and status. Ideally, in line with organizational needs, the management and leadership functions would be combined equally, considering that formal leader is recognized by her/his ability to simultaneously carrying out the management and leadership roles (Huber, 2016). Nurse Managers acting as a leader, so she/he is recognized as a promoter of care and relationships among colleagues (Baddar, et al., 2016).

Leadership considered the basic qualities for any nurse manager who spends most of her/his time with patients and caregiver, leadership is defined by Borick (2016) as the exercise of authority, whether formal or informal in directing and coordinating the work of others. Verghese (2016) added that leadership is the process of influencing and supporting others to work enthusiastically toward achieving objectives, also it is the process of directing and influencing the task related activities of group members.

Not all the nurse managers have the same leadership attributes levels, There are a wide range of attributes that distinguished effective and ineffective managers as assertiveness, self-awareness, accountability and advocacy, the first important attribute is nurse managers assertiveness which is defined as the honest and legitimate expression of one's personal opinions, needs, wants and feelings without denying or violating the rights of the others (Morse, et al., 2015).

Another important attribute for effective nurse managers is self-awareness which means being conscious of one's strengths and weakness. Nurse Manager must be able to assess his/her self in order to determine his/her needs for additional knowledge and skills (Duval \& Silvia, 2012). Csikszentmihalyi (2017) added that self-awareness is the ability to recognize the experiences, ideas and abilities that one experiences and others in the same time.

Accountability is considered the third important attributes by which nurse managers characterized a sense of organizational commitment to take whatever measures necessary for goal attainment and outcomes, openness in communication with staff and 
receptiveness' to feedback, and finally answerability for the process and outcomes (Quinn \& Griffin, 2016).

Finally the fourth attribute for effective nurse managers is to be advocating for patients present in her/his unit also advocating for nurses to increase their professional satisfaction, self-confidence, selfesteem \& maintain their personal integrity and moral principles advocacy which mean "observing a patients needs and finding a way to address and meeting them (Bu \& Jezewski, 2017)

Nurse Managers today face changeable degree of work stress which may or may not be considered the result of many variables, one from them first line nurse managers haven't satisfactory level of leadership attributes. So, work stress is defined by Sagar, et al. (2017) as the emotional and physical response that can be experienced by employees and caused imbalance between demands of employees and organization. Shaheen (2019) added that stress is a condition by which worker experienced changes disrupt her/his psychological or physiological conditions so individuals were forced to deviate from normal functioning

\section{Significance of the Study}

There's no studies were applied about nurse managers attribute and work stress levels nationally and internationally. This was the motive to assess a relation between nurse managers' attribute and work stress levels at Assiut University Hospitals. Many studies were done about work stress with different variables as work stress with nurse's job performance Jahangir, et al., (2014). Work stress and employee retention Masood (2016) One study was done about assertiveness and advocacy Morse, et al., (2015).

The present study aimed to; Determine first line nurse managers' attributes and work stress levels at Assiut University Hospitals.

\section{Specific Objectives}

- Determine first line nurse managers' assertiveness, accountability, awareness and advocacy levels.

- Assess the work stress levels among first line nurse managers.

- Determine the relationship between first line nurse managers' attributes and work stress level.

\section{Study Questions}

- Q1: What are attributes levels that first line nurse managers have?

- Q2: What are the levels of work stress for first line nurse managers?

- Q3: Is there a relationship between first line nurse manager's attributes levels and work stress levels?
Subject and Method

Technical design: It involves the research design, setting, subjects, and tools of data collection.

Research design: Descriptive correlational study design was used in present study.

Setting: The study was conducted at Assiut University Hospitals which contain (3395 beds) at 2018 and provide health care services to all upper Egypt customers from EL Mania to Aswan and include the following Hospitals ( Main Hospital, Pediatric Hospital, Women's Health Hospital, Urology and Nephrology Hospital, Neurology and Psychiatric Hospital, El- Orman Hospital, and EL- Rajhi Liver Hospital)

Study subject: The lowest number of first line nurse managers was in Urology and Nephrology Hospital no $=11$ so, the equal number was taken from all university Hospitals, and they randomly selected. First line nurse managers $=\mathbf{( 7 7 )}$.

Data Collection Tools; Two tools were used to collect data for the present study. Tool one: structure self-administer questionnaire sheet consists of five parts: $\mathbf{1}^{\text {st }}$ Part: Personal Data Sheet: It was used to collect data about first line nurse managers personal characteristics including; Hospital name, age, gender, educational qualifications, years of experience and marital status.

$2^{\text {nd }}$ Part: assertiveness scale: It was developed by Thompson \& Berenbaum, (2011) and modified by the same authors (2016) used to assess first line nurse' managers assertiveness levels and it consists of 30 statements. first line nurse' managers will be asked to respond to each statement using 6 points rating scale which ranged from (1) slightly like me, (2) rather like me, (3) very much like me, (-1) slightly unlike me, (2) rather unlike me and $(-3)$ very much unlike me. Scoring system; 1) If the first line nurse manager obtains scoring ranged from -90 to +19 , it means he/she had non- assertive behavior, 2) If the first line nurse manager obtains scoring ranged from 20 to +40 , it means he/she had assertive behavior, and 3) If the first line nurse manager obtains scoring ranged from + 41 to +90 , it means he/she had aggressive behavior.

$3^{\text {rd }}$ Part: Personal accountability scale which was developed by Boesen, (2017) used to measure personal accountability. It was consisted of 20 statements, responses will be measured on 5 points Likert scale which ranged from (1) Never, (2) Rarely, (3)Sometimes, (4) Usually, and (5 ) Always. Scoring system; 1) If the first line nurse manager obtains scoring $>70$ it means she/he had high level of accountability, 2) If the first line nurse manager obtains scoring from 70 to 50 it means she/he had medium level of accountability, and 3) If first line nurse manager obtains scoring $<50$ it means he/she had low level of accountability. 
$4^{\text {th }}$ Part: Johari Window Questionnaire which was developed by Luft \& Ingham, (1955) to measure selfawareness which consists of 20 statements every statement have A and B options the participant will be given score to $\mathrm{A}$ and $\mathrm{B}$ ranged from 0 to 5 according to how this statement representing him or her the total calculation of $\mathrm{A}$ and $\mathrm{B}$ will be equal 5 then the 20 statements was categorized under two classifications: (1) Solicits feedback it's the summary to calculate (2B ,3A ,5A ,7A ,8B ,10B ,12B, 14B, 16A,20A) then drawn on Johari window in the top axis. (2) Willingness to self-disclose gives feedback its summary to calculate (1A , 4B ,6B ,9B , 11B , 13A , 15A ,17B ,18B ,19B ). Then drawn on Johari window on the left axis and the participant awareness will be discovered

\begin{tabular}{|c|c|}
\hline $\begin{array}{llll}0 & 5 & 10 & 15 \\
20 & 25 & & \\
5 & \text { Open } & \\
10 & & & \\
15 & & \\
20 & & \\
25 & & & \end{array}$ & $\begin{array}{lllll}30 & 35 & 40 & 45 & 50 \\
& & & \\
& \text { Blind } & & \end{array}$ \\
\hline $\begin{array}{ll}30 & \\
35 & \\
40 & \\
45 & \\
50 & \end{array}$ & Unknown \\
\hline
\end{tabular}

(PNAS) which was developed by Hanks, (2015) and used to measure advocacy from the beliefs and actions of first line nurse managers, it consists of 43 -items scored on three-point Likert scale ranging from 3 (agree), 2 ( Eeither agree or disagree), and 1= (disagree) for each question. The PNAS questionnaire consists of the following four nurse advocacy components: (a) Acting as advocator (16 statements), (b) Work status and advocacy actions (5 statements), (c) Environment and educational influences (8 statements), and (d) Supporters and barriers to advocacy (14 statements ). Scoring system; 1) If the first line nurse manager obtains from 43 to 65 he/ she not advocate others, and 2) If the first line nurse manager obtains from 66 to 129 he/ she advocate others.

Tool two: Perceived Stress Scale; Which was developed by Cohen and Janicki (2015) and used to measure first line nurse managers work stress levels and it consists of 10 items, responses were measured using 5 points Likert scale which ranged from (0) Never, (1) Almost Never, (2) Sometimes, (3) Fairly often, and (4) Very often. Scoring system; Score interpretation will be varying according to the 10 statements, total score which equal $(40), 1)$ If the first line nurse manager achieves scoring ranged from 0 to
13 he/she would be experienced low level of stress, 2) If the first line nurse manager achieves scoring ranged from 14 to $26 \mathrm{he} / \mathrm{she}$ would be experienced moderate level of stress, and 3) If the first line nurse manager achieves scoring ranged from 27 to 40 he/she would be experienced high level stress.

Administrative design: An official approval to carry out the present study was obtained from the Dean of Faculty of Nursing Assiut University, and both (Medical and Nursing) Directors at all Assiut University Hospitals also all departmental Heads in order to be able to collect the necessary data.

Operational design: Explains steps of actual implementation of the study, usually includes; preparatory phase, the pilot, and field work.

Preparatory phase: This phase took up about three month from March to May 2019 which included reviewing the available literature concerning the study topic, study tools were prepared, and translated in to Arabic face validity was estimated by (5 Professors and Assistant professors from Nursing Administration and Community Health Nursing Departments) Faculty of Nursing Assiut University to make sure Arabic and English had the same

meaning (to test comprehension of study tools). Content validity: Measured by using confirmatory factors analysis to assure (Importance, Clearance, and Accountability) of all items of study tools, and its result were $\geq 1$ for all items, so all the tools items were confirmed

Pilot Study: Done to detect any problems that may be face the researchers during data collection phase. It helps also in estimating time needed to fill the questionnaire form. It was carried out on $10 \%$ first line nurse managers no. $=8$. The total period of data collection in the pilot study takes about one week. The participants chosen for the pilot study were excluded from the total study sample.

Reliability: Measured by using Cronbach's Alpha Coefficients methods to ensure internal consistency and its results were more than 0.8 for all items of all first line nurse managers questionnaire.

Field Work: The researcher met with each first line nurse managers in the study to explain the purpose of the study and to ask for participation. After obtaining oral agreement from them to participate in the present study, the study tools were then distributed to first line nurse mangers to be filled through self- administered questionnaire. Each participant took up between thirteen minutes to an hour to fulfill the questionnaire form. The whole duration for data collection took up about three months between May to August 2019.

Ethical considerations

Research proposal was approved from Ethical Committee at Nursing Faculty, Assiut University 
january 2019. The study followed common ethical principles in clinical research, then oral agreements were taken from all participants who participated in the present study, after informing them that they have the right to refuse/ participate/ withdraw from the study without any rational at any time, confidentiality and anonymity were assured, during collection of data participants were told that all obtained data were used only for purpose of

research.

Statistical Design: Analyzing and interpretation of data were performed using statistical software package for social sciences SPSS version 20, the data were tested for normality using the Anderson-Darling test and for homogeneity variances prior to further statistical analysis. Categorical variables were described by number and percentage where continuous variables described by means and standard deviation (Mean \pm SD).Using person Correlation to examine the association between Scores and linier regression to appear predictor factors for Total Stress Score. A twotailed $\mathbf{p}<\mathbf{0 . 0 5}$ was considered statistically significant.

\section{Results}

Table (1): Distribution of First line Nurse Managers Assertiveness Level Participated at the Present Study (no. $=77$ ).

\begin{tabular}{|l|c|c|}
\hline \multicolumn{1}{|c|}{ Assertiveness Levels } & No & $\%$ \\
\hline$-\quad$ Non- assertive & 35 & 45.4 \\
\hline$-\quad$ Aggressive & 21 & 27.3 \\
\hline- Total not assertive & 56 & $\mathbf{7 2 . 7}$ \\
\hline$-\quad$ Assertive & 21 & $\mathbf{2 7 . 3}$ \\
\hline
\end{tabular}

Table (2):- Distribution of First line Nurse Managers A Accountability Level Participated at the Present Study (no. $=77)$.

\begin{tabular}{|c|c|c|}
\hline Accountability Levels & No & \% \\
\hline- Low & 3 & $\mathbf{3 . 9}$ \\
\hline- Medium & 61 & 79.3 \\
\hline- High & 46 & $\mathbf{5 9 . 8}$ \\
\hline
\end{tabular}

Table (3): Distribution of Johari Window for Study subject (no.=77)

\begin{tabular}{|c|c|c|}
\hline Levels of awareness & No & $\%$ \\
\hline - Open & 13 & 16.9 \\
\hline - $\quad$ Behind & 14 & 18.2 \\
\hline - $\quad$ Unknown & 25 & 32.5 \\
\hline - $\quad$ Hidden & 25 & 32.5 \\
\hline
\end{tabular}

Table (4): Distribution of First Line Nurse Managers Advocacy Level Participated at the Present Study (no. =77).

\begin{tabular}{|l|c|r|}
\hline \multicolumn{1}{|c|}{ Levels of nursing Advocacy } & No & \% \\
\hline$-\quad$ Not advocate others & 11 & $\mathbf{1 4 . 3}$ \\
\hline- Advocate others & 66 & $\mathbf{8 5 . 7}$ \\
\hline- Mean \pm SD & \multicolumn{2}{|c|}{$74.29 \pm 8.25(47-99)$} \\
\hline
\end{tabular}

Table (5): Distribution of First Line Nurses Managers Stress Level Participated at the Present Study (no. =77).

\begin{tabular}{|c|c|c|}
\hline \multicolumn{1}{|c|}{ Levels of Stress } & No. & \% \\
\hline$-\quad$ Low & 8 & 10.4 \\
\hline- Moderate & 64 & $\mathbf{8 3 . 1}$ \\
\hline$-\quad$ High & 5 & $\mathbf{6 . 5}$ \\
\hline
\end{tabular}


Table (6): Relation between First Line Nurse Managers Attribute levels and Work Stress Levels among Assiut University Hospitals (no.=77)

\begin{tabular}{|c|c|c|c|}
\hline \multirow{2}{*}{ Nurse Managers Attributes } & \multicolumn{3}{|c|}{ Total Stress Score } \\
\hline & $\mathbf{N}$ & $\mathbf{R}$ & $\mathbf{P}$ \\
\hline \multicolumn{4}{|l|}{ Assertiveness Scale } \\
\hline - $\quad$ Non- assertive & 35 & 0.235 & 0.142 \\
\hline - $\quad$ Assertive & 21 & -0.224 & $0.05^{*}$ \\
\hline - $\quad$ Aggressive & 21 & 0.175 & 0.449 \\
\hline$-\quad$ Total & 77 & 0.255 & 0.225 \\
\hline \multicolumn{4}{|l|}{ Personal Accountability Scale } \\
\hline - Low & 3 & 0.500 & 0.667 \\
\hline - $\quad$ Medium & 28 & 0.247 & 0.205 \\
\hline- Good & 33 & -0.387 & $0.057^{*}$ \\
\hline$-\quad$ High & 13 & -0.314 & 0.056 \\
\hline - $\quad$ Total & 77 & 0.284 & $0.012^{*}$ \\
\hline Johari Window & 77 & -.024 & 0.05 \\
\hline \multicolumn{4}{|l|}{ Protective Nursing Advocacy Scale } \\
\hline - $\quad$ Not advocate others & 11 & 0.668 & 0.225 \\
\hline - $\quad$ Advocate others & 66 & -0.271 & 0.058 \\
\hline - $\quad$ Total & 77 & 0.343 & $0.002^{*}$ \\
\hline
\end{tabular}

Table (7): Comparison of First Line Nurse Managers Attributes and work Stress Levels among Assiut University Hospitals (no.=77)

\begin{tabular}{|c|c|c|c|}
\hline \multirow{2}{*}{ Hospital Name } & \multirow{2}{*}{ Attributes } & \multicolumn{2}{|c|}{ Total Stress Score } \\
\hline & & $\mathbf{R}$ & $\mathbf{P}$ \\
\hline \multirow[t]{4}{*}{ Main Hospital } & Assertiveness & .529 & 0.094 \\
\hline & Advocacy & .208 & 0.539 \\
\hline & Personal accountability & .166 & 0.625 \\
\hline & Awareness & .286 & 0.394 \\
\hline \multirow[t]{4}{*}{ Urology Hospital } & Assertiveness & $-.613^{*}$ & 0.05 \\
\hline & Advocacy & $-.726^{*}$ & 0.051 \\
\hline & Personal accountability & .197 & 0.561 \\
\hline & Awareness & .183 & 0.590 \\
\hline \multirow[t]{4}{*}{ Neurology Hospital } & Assertiveness & .523 & 0.099 \\
\hline & Advocacy & .301 & 0.368 \\
\hline & Personal accountability & .262 & 0.436 \\
\hline & Awareness & .455 & 0.160 \\
\hline \multirow[t]{4}{*}{ Pediatric Hospital } & Assertiveness & $-.698^{*}$ & 0.0519 \\
\hline & Advocacy & $-.706^{*}$ & 0.055 \\
\hline & Personal accountability & .204 & 0.547 \\
\hline & Awareness & .345 & 0.299 \\
\hline \multirow{4}{*}{$\begin{array}{ll}\text { Women } & \text { Health } \\
\text { Hospital } & \end{array}$} & Assertiveness & .309 & 0.356 \\
\hline & Advocacy & .072 & 0.834 \\
\hline & Personal accountability & .023 & 0.946 \\
\hline & Awareness & .273 & 0.417 \\
\hline \multirow[t]{4}{*}{ EL-Rajhi Hospital } & Assertiveness & .261 & 0.437 \\
\hline & Advocacy & $-.691^{*}$ & 0.018 \\
\hline & Personal accountability & $-.788^{*}$ & 0.0579 \\
\hline & Awareness & .162 & 0.635 \\
\hline \multirow[t]{4}{*}{ El-Oraman Hospital } & Assertiveness & .201 & 0.553 \\
\hline & Advocacy & $-.861^{* * \%}$ & 0.001 \\
\hline & Personal accountability & $-.604^{*}$ & 0.059 \\
\hline & - Awareness & .252 & 0.454 \\
\hline
\end{tabular}


Table (8): Multiple Regression Analysis between Stress Levels and First Line Nurse Managers Attributes among Assiut University Hospitals (no.=77)

\begin{tabular}{|l|c|c|c|c|c|c|}
\hline \multirow{2}{*}{ Nurse managers attributes } & \multicolumn{3}{|c|}{ Unstandardized coefficient } & \multicolumn{3}{|c|}{ standardized coefficient } \\
\cline { 2 - 7 } & $\mathbf{B e t a}$ & $\mathbf{T}$ & Sig & Beta & T & Sig. \\
\hline Assertiveness & $\mathbf{0 . 2 5 5}$ & 2.285 & $0.025^{*}$ & 0.191 & 1.736 & 0.087 \\
\hline Personal accountability & $\mathbf{0 . 2 8 4}$ & 2.566 & $0.012^{*}$ & 0.204 & 1.824 & 0.072 \\
\hline Protective Nursing Advocacy & $\mathbf{0 . 3 4 3}$ & 3.163 & $0.002^{* *}$ & 0.234 & 2.029 & $0.046^{*}$ \\
\hline Awareness & $\mathbf{- 0 . 0 6 8}$ & -0.590 & 0.557 & -0.004 & -0.040 & 0.969 \\
\hline
\end{tabular}

Dependent Variables is Stress Score

Table (1): Shows that the lowest percentage of first line nurse managers at Assiut University Hospitals were assertive $\mathbf{( 2 7 . 3 \% )}$, meanwhile more than two third of them their behavior were not-assertive (72, 7\%).

Table (2): Shows that the highest percent score of first line nurse managers at Assiut University Hospitals are accountable (59.8\%), meanwhile the lowest percent score of them had low level of accountability (3.9\%).

Table (3): Shows that the highest percent score of first line nurse managers at Assiut University Hospitals had unknown and hidden level of awareness $(\mathbf{3 2 . 5 \%})$, meanwhile the lowest percent score of them had open level of awareness (16.9\%).

Table(4): Shows that the highest percent score of first line nurse managers at Assiut University Hospitals advocating others $(\mathbf{8 5 . 7 \%})$, meanwhile the lowest percent score of them not advocating others (14.3\%).

Table(5): Shows that the highest percent score of first line nurse managers at Assiut University Hospitals had moderate level of stress $(\mathbf{8 3 . 1 \%})$, meanwhile the lowest percent score of them had high stress level $(6.5 \%)$.

Table (6): Illustrates that there was significant negative relation between first line nurse managers assertiveness, high personal accountability, advocacy, and awareness with work stress level $\left(\mathbf{0 . 0 5}^{*}\right)$.

Table (7): Illustrates that there was significant negative relation between first line nurse managers' advocacy and assertiveness with work stress at Urology Hospital and Pediatric Hospital. Lastly there was significant negative relation between first line nurse managers' advocacy and accountability with work stress at EL- Rajhi Liver Hospital and ElOrman Hospital.

Table (8): Reveals that the order of first line nurse managers attributes which impacted nurse managers stresses levels arranged as follows protective nursing advocacy, personal accountability, assertiveness and awareness.

\section{Discussion}

First line nurse managers typically report to nursing supervisors and carry out rules and policies that have been established by top and middle level nurse managers in the organization. Nurse Managers are involved in overseeing day-to-day operations or activities, including supervision of patients care also first line nurse managers delegate day-to-day tasks and responsibilities to nursing staff (Jones, et al., 2018).

First line nurse managers have many leadership attributes (Mandokhail, et al., 2018) added when first line nurse managers communicate in a way that express feeling, ideas, and thoughts without hurting other she/he become assertive. Hagemeister \& Volmer, (2018) added that first line nurse managers should be aware and accountable. Tomajan, (2015) explained that first line nurse managers must advocate patients, self, staffs, and assumed that all previous attributes may reduce work stress level.

From the findings of the current study, it is appeared that more than two third of first line nurse managers at Assiut University Hospitals their behavior were not-assertive (Table, 1). This might be because they are still suffering from bad nursing image in our community, so it lower her/ his self-esteem which in return translated aggressive behavior.

This finding was consistent with Rasetsoke, (2015) who mentioned that the majority of professional nurses in the Pretoria region had low self-confidence, high conflict situation and non-assertive behavior. On the contrary with this finding El-Din, (2013) who found that the majority of nurses were assertive, also Abdel-Aleem, (2009) mentioned that the majority of head nurses as well as nurses are assertive, also result of Ilyas, et al., (2018) was opposite to present study finding as they found that slightly more than half of nursing managers had high assertiveness level.

From the findings of the current study, it is appeared that more than half of first line nurse managers at Assiut University Hospitals were accountable (Table, 2). This result may be attributed to first line nurse managers are accountable for accept consequences that occur as a result of their actions.

This finding is consistent with American Nurse Association (ANA), (2015) which reported that nurses have authority in every role, and are accountable for the quality of the care they provided, 
Also this finding consistent with Sorensen, et al., (2019) as they found that accountability level was high among nurses manager.

This finding is inconsistent with study done by Shahriari \& Baloochestani, (2017) as they found that senior nurses less accountable than junior nurses and they also found that most junior nurses who enter the nursing profession want to avoid mistakes, which affects their perceived accountability.

From the findings of the current study, it is appeared that the lowest percent score of first line Nurse Managers were aware of them self and others (open) but the majority of them not aware either for them self or for others unknown (table 3). This result may be attributed to first line Nurse Managers unable to explore inner side of personality, not able to analyze others personality and cannot communicate effectively with nursing staff due to work load and inability to build relationship with nursing staff this leads to unawareness.

This finding is consistent with the findings of a study done by Ducinskiene, et al., (2016) as they found that the lowest percent score of first line Nurse Managers as experienced open level of awareness. This finding is in congruent with Nejad, et al., (2017) they found that the majority of first line nurse managers have good awareness level (open).

From the findings of the current study, it is appeared that the majority of first line Nurse Managers at Assiut University Hospitals advocating others (Table, 4). This might be because first line Nurse Managers are defending patients and nurses to protect their rights in the health care environment, help patients to participate in decisions making pertaining to him/ her.,

This finding goes in the same line with Negarandeh et al., (2018) as they found that first line Nurse Managers protecting their patients as well as protects nurses in their wards and they summarized that protecting patients is one of the key factors of patients care quality, Ware, et al., (2016) reported that all American nurses advocating their patients.

From the findings of current study result it is depicted that the highest percent score of first line Nurse Managers at Assiut University Hospitals had moderate level of stress, meanwhile the lowest percent score had high stress level (Table, 5). This might be because lack of mutual understanding between first line Nurse Managers, and physicians (especially newly employed physician), work overload, increase family obligations as the majority of them were married, working long shift (12 hour shift) and working night shift all those predisposing factors contributes to increase stress level.

This finding is agree with studies done by Bhatia, et al., (2015), Nabirye,et al., (2016) \& Mozhdeh,et al.,
(2018), all the previous studies summarized that the majority of nurse managers experience moderate levels of work stress.

From the findings of the current study, it is appeared that there was negative relation between first line Nurse Managers' assertiveness, personal accountability, advocacy, and awareness with work stress level (Table, 6). This might be because assertive first line Nurse Managers who able to express feelings, ideas, thoughts without hurting or ignoring rights of others in the same time she/ he accountable about their actions, had authority equal to their responsibilities able to advocate their patients and had open awareness level, all this characteristics if the first line nurse managers had will help her in dealing with conflict in suitable manner which in return helping decrease work stress level.

The present study congruent with study done by Negarandeh, et al., (2018) as they found that there were negative relation between work stress and nurses advocacy. This finding also is consistent with Goodman, et al., (2017) they mentioned that individuals who perceive high level of accountability experience less work stress level. This finding also goes in the same line with Maheshwari \& Gill, (2018) as they found that there significant negative relation between assertiveness with work stress level for both nurses and physicians.

Also the present study finding is congruent with study done by ANA report, (2015) \& Sorensen, et al., (2019), which supported that as soon as nurse become accountable and had significant authority their work stress level decreased so there is negative relation between level of accountability and work stress level. The present study finding goes in the same line with study done by Nejad, et al., (2017) as they found that there is significant negative relation between nurse's awareness and occupational stress level.

From the findings of the current study, it is appeared that there was significant negative relation between first line Nurse Managers' advocacy and assertiveness with work stress at Urology Hospital and Pediatric Hospital (Table, 7). This might be attributed to the first line Nurse Managers at Urology Hospital and Pediatric Hospital standing up for their ideas and feeling without hurting others also they advocate patients' rights so, work stress level was decreased among them.

This finding is consistent with Maheshwari \& Gill, (2018) as they found that there significant negative relation between assertiveness and nurses work stress level. But Goodman, et al., (2017) findings not congruent with the present study finding as they found that there is no significant relation between first line nurse managers' advocacy and assertiveness with work stress level. 
From the findings of the current study, it is appeared that there was significant negative relation between first line Nurse Manager's advocacy and accountability with work stress at El- Rajhi Liver Hospital and El- Orman Hospital (Table, 7). This might attributed to first line nurse managers at ElRajhi and El- Orman Hospitals was knowledgeable enough about patients' rights and their role in advocating patient rights as their administrator communicating patient rights through printed pannier present in every department corridors.

This finding is was consistent with Goodman, et al., (2017) \& Ware,et al., (2016) they indicated that individuals who perceive higher accountability become less stressed, also Nejad, et al., (2017) support this finding as they found that nurses' advocacy and accountability had significant related with work stress level.

From the findings of the current study, it is appeared that the order of attributes that first line Nurse Managers had and impacted their stress levels arranged as follows; protective nursing advocacy, personal accountability, assertiveness and awareness (Table, 8). This might be attributed to first line nurse managers work stress as a result of heavy workload which affected firstly by the nursing advocacy for self and others, secondly, they have the authority and accountability to make decisions and therefore responsibility relies on them to make changes and provide enough resources and support and thirdly must know their rights and support rights of others.

\section{Conclusions}

In the light of the present study findings, the following conclusions can be drawn as:

- More than two third of first line Nurse Managers behavior were not-assertive, but the highest percent score of them having good level of accountability, advocating others, as regarding awareness the lowest percent score had open level of awareness and the highest percent score of them had moderate level of work stress.

- There was significant negative relation between assertive, high personal accountability, advocacy, and awareness with work stress level.

\section{Recommendations}

In the light of the study results, the following recommendations will be suggested

1- Developing and implementing strategies to coping with stress levels which facing first line nurse managers work stress level.
2- Developing and implementing continuous educational programs to improve first line nurse managers' awareness and assertiveness levels.

3- Further research study should be done to study the relation between first line nurse managers attributes and productivity.

\section{References}

1. Abdel-Aleem, M., Ibrahim, S., \& El-Shimy, H., (2009): Factors Affecting Assertiveness among Head Nurses and Staff Nurses at Suez Canal University Hospital, Zagazig Nursing Journal, 5(2), Pp.1-12.

2. American Nurses Association, (2015): Code of Ethics for Nurses Retrieved from http://www.nursingworld.org/code-ofethics.

3. Baddar, F., Salem, O., Villagracia, H., (2016): Conflict Resolution Strategies of Nurses in a Selected Government Tertiary Hospital in the Kingdom of Saudi Arabia, 6(5): P.p.91.

4. Bhatia, N., Kishore, J., Anand, T., \& Jiloha, R., (2015): Occupational Stress amongst Nurses from Two Tertiary Care Hospitals in Delhi, Australasian Medical Journal (Online), 3(11), P.p.731..

5. Boesen, L.,

(2017): http://www.lisaboesen.com/new/wpcontent/u ploads $/ 2017$

6. Borick, S., (2016): Introducing Administration, Leadership, $8^{\text {th }}$ ed, chap. (10), Publisher: Pearson, Pp. 361-362,

7. Bu, X., \& Jezewski, M., (2017): Developing a Mid-Range theory of patient advocacy through concept analysis, Journal of Advanced Nursing, 57(1), Pp. 101-110.

8. Cohen, S., \& Janicki, D., (2015): Who Stressed, Distributions of Psychological Stress in the United States in the Probability Samples, applied psychology journal, 42( 6), P.p. 1320-1334.

9. Csikszentmihalyi, M., (2017): Toward a Psychology of Optimal Experience. In Flow and the Foundations of Positive Psychology, pp. 209-226.

10. Ducinskiene, D., Vladickiene, J., \& Haapala, I., (2016): Awareness and Practice of Patient's Rights Law in Lithuania. BMC international health and human rights, 6(1), P.p.10-12.

11. Duval, T., \& Silvia, p., (2012): Self Awareness, Probability Improvement and the Self -Serving, Journal of personality and social psycology,82(1),P.p. 49-61. 
12. El Din, S., (2013): Factors Affecting Assertive Behavior of Nurses Working in Different Units in Cairo university hospitals, unpublished master thesis, Cairo University, Egypt, Pp. 58-65.

13. Goodman, J., Evans, W., \& Carson, C., (2017): Organizational Politics and Stress: Perceived Accountability as a Coping Mechanism, The Journal of Business Inquiry, 10(1), P.p.66-80.

14. Hagemeister, A., \& Volmer, J., (2018): Do Social Conflicts at Work Affect Employees' Job Satisfaction? The moderating role of emotion regulation, International Journal of Conflict Management, 29(2), pp.213-235.

15. Hanks, R., (2015): The Medical-Surgical Nurse Perspective of Advocate Role. Nursing Forum, 45(2), P.p. 97-107.

16. Harris, N., (2015): Nursing service and administration, organization, $1^{\text {st }}$ ed. chap.3, ,published by virenderkumar publishers, P.p.17,90,148.

17. Huber, D., (2016): Leadership and Nursing Care Management. 5th edition. Missouri: Elsevier.

18. Ilyas, U., Afzal1, M., \& Gilani, S., (2018): Assertive Behavior of Nurses and Head nurses in Government Hospital Lahore, Pakistan,4 (3) , P.p .77-87

19. Jahangir, M., Kareem, N., Khan, A., \& Jan, M., (2014): Effects of Job Stress on Job Performance, Interdisciplinary journal of contemporary research in business, 3(7), P.p .453-465.

20. Jones, C., Finkler, S., \& Mose, J., (2018): Financial Management for Nurse Managers and Executives-E-Book. Elsevier Health Sciences.

21. Luft, J., \&Ingham, H., (1955):'The Johari window, a graphic model o f interpersonal awareness": University of California, Los Angeles.

22. Maheshwari, S., \& Gill, K., (2018): Relationship of Assertive Behavior and Stress among Nurses, Delhi Psychiatry Journal, 18(2), P.p.356-364.

23. Mandokhail, S., Khan, F., \& Malghani, M., (2018): Impact of ESL Learners' Self-Esteem on their Oral Proficiency, International journal of English linguistics, 8(3), P.p.210-222.

24. Masood, A., (2016): Effects of Job Stress on Employee Retention: a study on banking sector of Pakistan, International Journal of Scientific and Research Publications, 3(9), P.p.1-8.
25. Morse, G., Salyers, M., \& Rollins, A., (2015): Burnout in Mental Health Services: A review of the problem and remediation. its Administration and Policy in Mental Health, 97(1):pp. 97-101.

26. Mozhdeh, S., Hajian, E., Malbousizadeh, M., (2018): Relationship between Nurse's Stress and Environmental-Occupational Factors, Iranian Journal of Nursing and Midwifery Research, 13(1).

27. Nabirye, R., Brown, K., \& Maples, E., (2016): Occupational Stress, Job Satisfaction and Job Performance among Hospital Nurses in Kampala, Uganda, Journal of nursing management, 19(6), P.p. 760-768.

28. Negarandeh, R., Oskouie, F., \& Nikravesh, M., (2018): The meaning of patient advocacy for Iranian nurses,Nursing ethics Journal, 15(4), P.p.457-467.

29. Nejad, E., Begjani, J., \& Ehsani, S., (2017): Nurses Awareness of Patients' Rrights in a Teaching Hospital, Journal of medical ethics and history of medicine, 4.

30. Quinn, M., \& Griffin, M., (2016): Nursing Concept Analysis ,chap. (2), caregiver-focused concepts, springer publishing company, $\mathrm{P}(218)$.

31. Rasetsoke, R., (2015): Assertive Behavior of Professional Nurses and Nurse Managers in Unit Management in Pretoria Region (Doctoral dissertation, University of Johannesburg).

32.Sagar, S., Ravish, K., \& Shanmugapriya, D., (2017): Professional Stress Levels among Healthcare Workers a cross sectional study,International Journal Of Community Medicine \& Public Health, 4(12),Pp 46854691.

33. Shaheen, F., (2019): A study of Parental Expectations, Attribution Styles and Coping (Doctoral dissertation, Aligarh Muslim University).

34. Shahriari, M., \& Baloochestani, E., (2017): Applying Professional Values: The Perspective of Nurses of Isfahan Hospitals, Journal of Medical Ethics and History of Medicine, 7(1), P.p. 1-7.

35. Sorensen, E., Seebeck, E., \& Loes, J., (2019): The Relationship between RN Job Satisfaction and Accountability, Western Journal of Nursing Research, 31(7), P.p. 872888.

36. Thompson, R., \&Berenbaum, H., (2016): Adaptive and Aggressive Assertiveness Scales, Journal of psychopathology and Behavioral assessment,33(3), P.p 323-334. 
37. Tomajan, K., (2015): Advocating for Nurses and Nursing. OJIN: The Online Journal of Issues in Nursing, 17(1), p. 4.

38. Verghese, C., (2016): Nurse Administrator, , Management Nursing: Definition, Concept , Scope, and Practice , $1^{\text {st }}$ ed, chapter(2), P.p 173-174..

39. Ware, L., Bruckenthal, P., \& O'Conner S., (2016): Factors that Influence Patient Advocacy by Pain Management Nurses: Results of the American Society for Pain Management Nursing Survey, 12(1), P.p.25-32 